\title{
Reserves 'win-win' for fish and fishermen
}

\section{SAN DIEGO, CALIFORNIA}

Although fisherman routinely fight bans on fishing, studies indicate that the creation of protected marine reserves in key areas can both raise the profits of fishermen and boost fish populations. Researchers presented evidence of these dual benefits in several sessions over the past week at the annual meeting of the American Association for the Advancement of Science (AAAS) in San Diego, and in a suite of papers published in the Proceedings of the National Academy of Sciences.

Marine reserves could help to make nearby fisheries profitable by acting as nurseries for fish larvae that are later spread by ocean currents, for example. "Reserves allow a win-win situation better conservation and higher profitability for fishing," says Christopher Costello, a resource economist at the University of California, Santa Barbara (UCSB). His group's modelling study of southern Californian waters suggests that fishing profits are maximized when significant areas are closed to fishing ${ }^{1}$.

Steven Gaines, a UCSB marine ecologist who organized an AAAS symposium on marine reserves, adds that his own team's research with ocean circulation models shows that protected areas do not need to be extensive. Strategic positioning of smaller reserves in a network can create pathways for fish outside protected zones, which can boost the yields of fishermen.

Research on one of the world's largest marine conservation efforts, along Australia's Great Barrier Reef, shows how quickly such efforts can make a difference. Nearly one-third of the 2,000-kilometrelong reef off Queensland is set aside as 'no-take' zones, after stringent controls were put in place in 2004.

Terry Hughes, director of the Australian Research Council's Centre of Excellence for Coral Reef Studies in Townsville, Queensland, said at the symposium that his team's reef research ${ }^{2}$ found that, in the no-take zones he studied, overall fish densities have doubled since they were created. On some reefs, the population of certain species, such as grouper, doubled within just two years of fishing closures. "The reef generates far more economic benefit to Australia than the cost of protecting it," he adds, estimating that the costs are less than $1 \%$ of annual revenue generated from other reef activities, such as tourism.

The experience of the Great Barrier Reef could inform an ongoing debate in California. The state is involved in a contentious process to create networks of reserves that could eventually encompass $10-20 \%$ of the state's coastline and stretch up to 5 kilometres from shore.

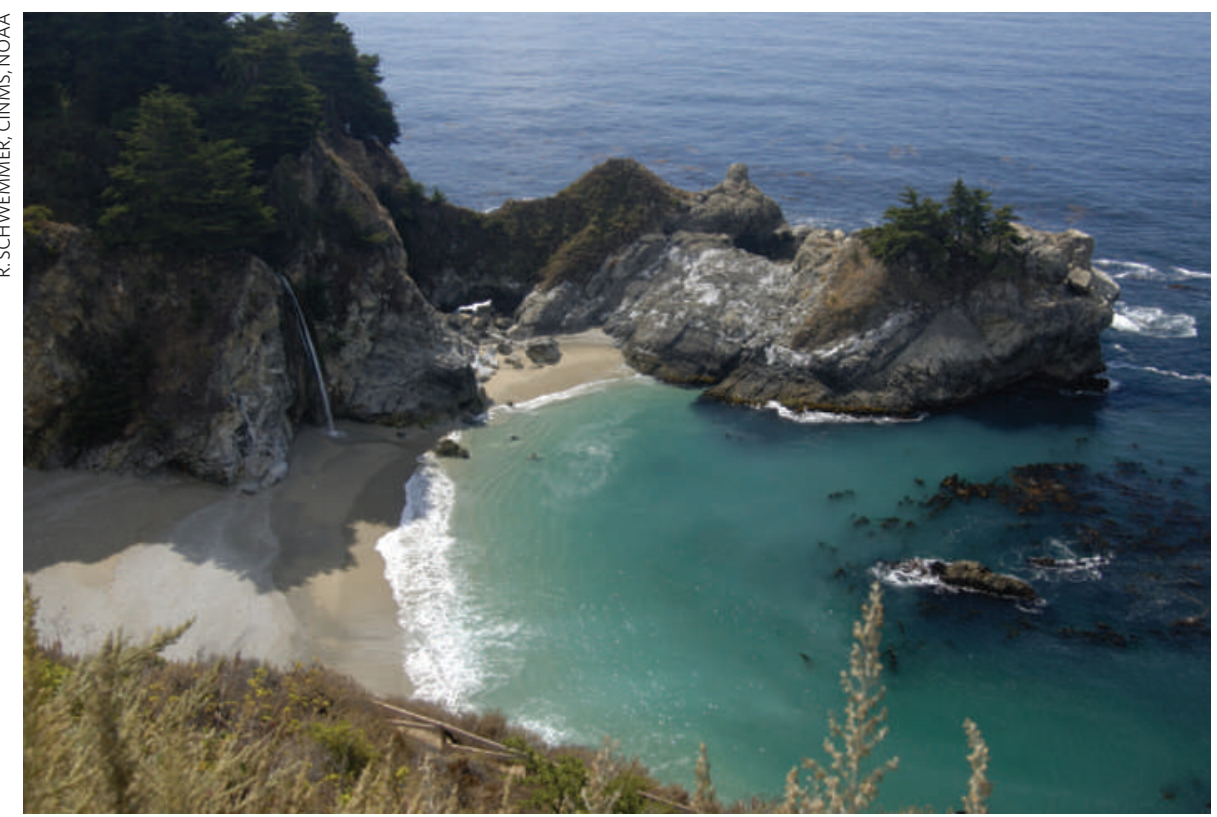

The diverse ecosystem of California's Monterey Bay is the focus of a National Marine Sanctuary.
The Marine Life Protection Act was approved by Californian voters in 1999, but attempts to establish the reserves it mandated have been delayed by strong resistance. The battle between marine conservationists and fishermen has become so bitter that armed game wardens now attend public hearings about the plan. Fist fights have broken out at some meetings and, at one, Paul Dayton, a marine biologist at the Scripps Institution of Oceanography in La Jolla, was spat at by a fisherman.

A reserve system has so far been adopted for two regions along the central coast; a plan for a southern coastal region is under review; and plans are to be developed for the final two areas by the end of 2011.

Many complain that the scheme is too costly, and argue that there is little evidence that reserves successfully protect marine wildlife. But marine biologist Jennifer Caselle at the UCSB and her colleagues have put paid to this claim ${ }^{3}$.

Her team studied ten no-take and two fishing-restricted zones created in 2003 within the 100-kilometre-long Channel Islands National Marine Sanctuary off Santa Barbara. The scientists found that the number and size of the fish targeted for protection was greater in the reserve than outside. They also found that the ecosystem was healthier overall, with more predators such as spiny lobster and California sheephead helping to keep sea urchins under control. Because the urchins graze on kelp - an important habitat for many fish species - Caselle says that "the increased abundance of predators may help to prevent the transition of productive kelp forests into unproductive urchin barrens".

The research was greeted cautiously by Norman de Vall, president of Redwood Coast Watersheds Alliance in Elk, California, where reserve planning is now under way. Even if reserves produce larvae that move into unprotected areas, that may not be enough to help fishermen, says de Vall, a former commercial fisherman. What is needed, he said, is smarter management of fishing stocks overall and "less fishing everywhere".

Rex Dalton

1. Costello, C et al. Proc. Natl Acad. Sci. USA doi.10.1073/ pnas.0908057107 (2010)

2. McCook, L. J. et al. Proc. Natl Acad. Sci. USA doi:10.1073/ pnas.0909335107 (2010).

3. Hamilton, S. L., Caselle, J. E., Malone, D. P. \& Carr, M. H. Proc. Natl Acad. Sci. USA doi:10.1073/pnas.0908091107 (2010). 